negative and $1(0.5 \%)$ not tested for HBsAg. Of the HBcAb-positive individuals, requesting details were available for 10 cases: for $8 / 10$ both $\mathrm{HBsAg}$ and $\mathrm{HBcAb}$ were requested initially.. Of $178(89.0 \%) \mathrm{HBcAb}$-negative individuals, HBsAg was performed for 49 (24.5\%); all were HBsAg-negative. Across the Trust, $11,500 \mathrm{HBcAb}$ tests were requested in 12 months. Assuming 89.0\% HBcAb-negativity, the cost of testing $24.5 \%$ of these patients for HBsAg would almost reach $£ 10,000$.

Results Reducing HBsAg testing in HBcAb-negative individuals would provide savings. Reflex laboratory HBsAg should be implemented for HBcAb-positive patients.

\section{P188 SAFEGUARDING ADULTS ATTENDING AN INNER CITY SEXUAL HEALTH SERVICE}

Nisha Mody, Catherine Kirby*, Patrice Grech, Hermione Thompson, Frances Turner, Lorette Runacres, Elizabeth Hamlyn. King's College Hospital, London, UK

\section{$10.1136 /$ sextrans-2016-052718.238}

Background/introduction Adult safeguarding is the process of protecting vulnerable adults from harm or exploitation. In 2014 our sexual health clinic introduced an adult safeguarding proforma and a regular adult safeguarding meeting.

Aim(s)/objectives To evaluate the impact of a new safeguarding pathway.

Methods Retrospective case note review of patients entered onto the safeguarding database from April-December 2015.

Results Of 14833 adult attendances, 148 patients were identified as vulnerable $(1.0 \%$ vs $0.3 \%$ in $2013, \mathrm{p}<0.0001)$. Notes were available for $135 / 148$. Median age was 30 years (range 18-70); $74 \%$ female; $17 \%$ homosexual or bisexual. Main reasons for attendance were STI screening (69\%) and contraception (11\%). $13 \%$ of females were pregnant. Vulnerability was identified by the clinician in $64 \%$ and disclosed by the patient or carer in $27 \%$. Mental health problems were reported in 60\%; a violent or pressurised relationship in 53\%; drug or alcohol consumption in $55 \%$. $13 \%$ were asylum seekers; $7 \%$ were victims of trafficking. $7 \%$ had learning disabilities. $4 \%$ reported sex with a person in a position of trust. Two or more vulnerability factors were identified in $86 \%$. 2\% lacked capacity. $70 \%$ were discussed at the Adult safeguarding meeting, 27\% were referred to the Trust safeguarding team. Other referrals included social services (7\%), mental health services (5\%) and police (3\%). 14\% had responsibility for children aged $<18$ years; $5 \%$ required child safeguarding input.

Discussion/conclusion A large number of vulnerable adults attend our service, highlighting the importance of robust safeguarding procedures. Greater numbers were identified following introduction of a new safeguarding pathway.

\section{P190 SEXUAL HEALTH APPOINTMENTS BY TEXT ONLY: SPEED, SAVINGS AND SATISFACTION}

Annette Thwaites, Dale Coley, Eleanor Draeger*. Lewisham and Greenwich NHS Trust, London, UK

\subsection{6/sextrans-2016-052718.239}

Background/introduction When setting up an appointment-based specialist GUM service within our walk-in community sexual and reproductive health service we took the opportunity to send patients their appointment details by text message rather than letters. We also send reminder texts prior to the appointment, in an attempt to reduce "Did not attend" (DNA) rates.

Aim(s)/objectives To estimate associated cost savings and patient satisfaction with the use of texts instead of appointment letters.

Methods Cost saving calculations considered costs of sending texts relative to stationery and postage and a time and motion study to estimate relative staff costs. DNA rates 6 months before and after the implementation of the text reminder service were compared using Fisher's exact test. A satisfaction survey of a random sample of patients attending the booked GUM clinics included basic demographic questions and questions about the use of appointment and reminder texts.

Results There was an estimated cost saving of $88 \mathrm{p}$ per appointment.

\begin{tabular}{|c|c|c|c|}
\hline & May-Nov 2013 & Dec 13 - Jun 2014 & \\
\hline GUM Appointments & 2118 & 1683 & \\
\hline GUM DNAs & 589 & 355 & \\
\hline DNA Rate & $27.81 \%$ & $21.09 \%$ & $P=<0.001$ \\
\hline
\end{tabular}

28 satisfaction surveys were completed. $82 \%$ preferred to get their appointments solely by text.

Discussion/conclusion The use of text messages instead of letters has saved the clinic money and time, and is popular with patients. Our Trust offers 500,000 outpatient appointments per year. If only half of those were booked by text instead of letter, the trust could save more than $£ 220,000$ per year.

\section{P191 ESTABLISHING AN INTEGRATED LEVEL 2 SEXUAL HEALTH SERVICE FOR PEOPLE WITH LEARNING DIFFICUTIES}

Gill McCarthy*, Marion Norbrook. Kingston Hospital Foundation Trust, Kingston upon Thames, UK

\subsection{6/sextrans-2016-052718.240}

Background/introduction A local needs assessment by Public Health in 2013 identified an unmet need for sexual health services for young people (13-25 years) with learning difficulties. Public Health identified funding and developed a service specification for a local level 2 sexual service that was tendered for a pilot period of 15 months. We were successful in bidding for the service.

Aim(s)/objectives We describe our journey in establishing a bespoke sexual health service for people with learning difficulties as part of our level 3 Sexual Health and HIV service. We outline the difficulties we encountered, how we overcame them and highlight learning points for other providers wishing to establish similar services.

Methods A descriptive analysis of the clinic history, service provision, staff training, clinic activity and STI and contraception diagnoses. The complexity of individual cases is captured by brief case histories.

Results The service delivery model is multidisciplinary and was developed in collaboration with all key stakeholders including the users themselves. An initial survey identified a community site co-located with the community paediatric service for disability and a Friday afternoon after school as the preferred options. We advertised the service widely including all schools for children with special education needs, social services and carers and 